\title{
Cow-Calf Producer Preferences for Voluntary Traceability Systems
}

\author{
Lee L. Schulz and Glynn T. Tonsor ${ }^{1}$
}

(Original submitted March 2009, revision received August 2009, accepted October 2009.)

\begin{abstract}
This article identifies preferences of US cow-calf producers for voluntary traceability systems to better identify the potential success of alternative voluntary traceability systems. Results suggest that notable heterogeneity exists between cow-calf producers in their preferences and the welfare effects of mandating traceability adoption. Producers are sensitive to price, managing entity and information requirements. We provide forecasts of voluntary participation rates under different price premium and discount scenarios that producers may face. This analysis has policy implications as success of voluntary traceability systems hinges critically upon cow-calf producer preferences.
\end{abstract}

Keywords: Animal traceability; cattle producer; cow-calf; National Animal Identification System; voluntary traceability.

JEL classifications: $Q 12, Q 18, R 38$.

The National Animal Identification System (NAIS) is an information system consisting of premises registration, animal identification and animal tracing, that helps producers and animal health officials respond quickly and effectively to animal disease events in the USA (USDA-APHIS, 2008a). Producers who choose to participate in NAIS become part of a national animal disease response network, where all three of the NAIS components are used together to provide a streamlined system of information (USDA-APHIS, 2007). In order for NAIS to be most effective and provide a full traceable history of animal movements, premises registration, animal identification and animal tracing are needed for the cow-calf sector. Initial deadlines for full implementation and compliance of NAIS have elapsed with participation rates for the establishment of individual premises identification and individual

\footnotetext{
${ }^{1}$ Lee L. Schulz is a Graduate Research Assistant in the Department of Agricultural Economics, Kansas State University, 342 Waters Hall, Manhattan, KS 66506, USA. E-mail: leeschulz@agecon.ksu.edu for correspondence. Glynn T. Tonsor is an Assistant Professor in the Department of Agricultural, Food, and Resource Economics, Michigan State University. The authors acknowledge, without implication, BEEF Magazine for providing the mailing list for our survey, and two anonymous reviewers and the editors for comments on earlier versions of this paper.
} 
animal identification below expectation (USDA-APHIS, 2008a). USDA estimates show that only $35 \%$ of producers register their premises, which is the minimal requirement for participation in NAIS (USDA-APHIS, 2009). This creates a critical need we aim to meet in this article in identifying producer preferences and determining how traceability systems could be designed and promoted to improve voluntary participation rate. ${ }^{2}$

Any voluntary system hinges critically on the preferences of potentially participating parties. As cow-calf producers are the foundation of the beef supply chain, their preferences in the design of an individual animal traceability system are critical (Schulz and Tonsor, 2008). According to Souza Monteiro and Caswell (2004), 'four patterns of adoption are evident in the major producing and trading countries: adoption of mandatory systems in response to consumer concerns (EU and Japan), imposition of mandatory traceability to maintain or enhance export shares (Australia, Brazil, and Argentina), industry managed mandatory programs for animal identification (Canada), and voluntary systems (United States)' (p. 7). Furthermore, in case studies of beef firms employing traceability located in France, Holland, Germany, Norway and Scotland, Buhr (2003) states, 'When case participants were asked why they adopted traceability, the first response in every case was, "Consumers demanded to know where their food came from and how it was produced"' (p. 14). Surprisingly, very little research has examined preferences of US cow-calf producers regarding traceability systems. This is a substantial gap from a public policy standpoint. For example, NAIS has a stated goal of improving the USA's disease response capabilities, limiting the spread of diseases, minimising animal losses and economic impacts, protecting producers' livelihoods and maintaining market access (USDA-APHIS, 2008b). However, the effectiveness of NAIS in its current form is dependent upon voluntary participation of livestock producers.

Golan et al. (2004) report the existence of several beef traceability systems in the USA, although current traceability systems have been mainly private and market driven. 'There are currently no mandatory beef traceability systems in the U.S.' (Souza Monteiro and Caswell, 2004, p. 20). As a result, differences exist between traceability systems developed by private firms and those mandated or influenced by public authorities (Souza Monteiro and Caswell, 2004). Moreover, the USA may be lagging behind other countries in adoption of livestock traceability systems, thereby, decreasing its competitiveness in the global beef market (Tonsor and Schroeder, 2006). This can be attributed to the low adoption of traceability systems by the cow-calf sector, as efficient and effective traceability systems allow for trace back to the point of origin.

The primary objective of this article was to examine cow-calf producer preferences for voluntary traceability systems. Our analysis involves evaluating how sensitive producer preferences are to premiums and discounts, the entity in charge of data maintenance and the amount of information required for producer participation. Identification of cow-calf producer preferences allows forecasting voluntary participation rates under different scenarios producers may face. Producer welfare effects of imposing mandatory traceability are also provided. This study is the first

\footnotetext{
${ }^{2}$ Throughout this analysis we use the term 'traceability' to refer to live animal traceability, rather than meat traceability.
} 
known evaluation aimed at improving understanding of how design of an individual animal traceability system impacts voluntary participation by producers and of the corresponding welfare effects.

The remainder of the article is organised as follows. First, a review of previous research is presented to highlight the need for further analysis. The next section shows the methods used for producer-level data collection, the layout of the conceptual random utility model, and discussion of estimated multinomial logit and latent class models (LCMs). Producers' willingness-to-change (WTC) traceability system attributes, forecasts of alternative traceability system participation and producer welfare effects are then examined. The final sections provide a discussion of implications and conclusions.

\section{Previous Research}

The NAIS was initiated to enhance previous disease programmes through the establishment of standards that could be used for all state and federal disease programmes in the USA. The focus of NAIS is on animals that enter commerce, that is, those animals that move from their farm and ranch to markets and/or locations where they co-mingle with animals from other premises (Cattle Network, 2008). According to Murphy et al. (2009), 'NAIS was originally designed as a mandatory program, but due to strong opposition, the USDA changed directions and published a revised "User Guide" in November 2006, which stated that NAIS would become a voluntary program at the federal level' (USDA-APHIS, 2007, p. 3). The NAIS is the broadest and most comprehensive effort ever launched in the USA to enhance the ability to quickly identify and contact animal premises, promote animal identification and develop animal movement and tracing capabilities (Schroeder et al., 2009).

Several studies have compared current traceability systems that exist in the global beef market. According to Murphy et al. (2008), 'North America recognizes that systems that can protect the integrity of national livestock populations, as well as strengthen consumer and export market confidence in meat products are becoming prerequisites to international trade' (p. 284). For example, Murphy et al. (2009) state 'the existence of the Canadian Cattle Identification Agency (CCIA) sends a very clear message to the world that Canada takes identification and traceability of its animals very seriously' (p. 8). Tonsor and Schroeder (2006) argue that the US beef industry lags behind Australia in animal traceability. Along these same lines, Smith et al. (2005) reported that the USA is 'lagging behind many countries in developing traceability systems for food in general and especially for livestock, and their products' (p. 174). Souza Monteiro and Caswell (2004) present evidence that EU, Japan, Australia, Brazil, Argentina and Canada lead the USA in beef traceability systems. Bailey (2007) demonstrates the USA has a weaker beef traceability system than Uruguay, Argentina, the European Union and Australia. Collectively, these studies suggest that traceability adoption in the USA is falling behind other leading beef-producing countries. Although there exists a significant body of literature comparing traceability systems and identifying shortcomings, better identification of the potential success of alternative voluntary traceability systems that could exist in the beef industry is needed.

Past research has sought to analyse consumers' preferences towards voluntary traceability (Dickinson and Bailey, 2002; Dickinson et al., 2003). This work has 
primarily been done through experiments where consumers bid on products that are labelled with differing levels of traceability. The key point to take from these analyses was that traceability, while receiving positive bids, was the least valued of the three individual characteristics presented to consumers (i.e. animal welfare, food safety and traceability). Dickinson et al. (2003) suggested that traceability should be bundled with other characteristics that could be verified with traceability when food products were marketed with these characteristics.

In response to beef safety issues 'the EU has developed a system for identification and registration of cattle and a compulsory traceability and labeling system that allow the flow of product information throughout the supply chain' (Gracia and Zeballos, 2005, p. 45). ${ }^{3}$ Gracia and Zeballos (2005) evaluated whether the beef supply agents recognised benefits from the implementation of the traceability system. Perceptions of the new traceability regime were mostly consistent amongst consumers and retailers. Consumers and retailers commented that the new mandatory traceability programme led to higher beef prices and is unnecessary because the quality and safety of beef was already adequate before the system was developed; whereas consumers believed the new system increased consumer safety perceptions and confidence and retailers believed benefits were accrued by consumers, retailers and the rest of the players in the beef supply chain (Gracia and Zeballos, 2005).

There has been little research on producers' preferences concerning voluntary traceability. This is especially important when attempting to implement individual animal traceability and maximise participation rates of these systems as the views of these producers will most certainly impact the success or failure of these efforts. A few recent economic studies have addressed beef industry perceptions regarding traceability. Buhr (2003) focused on the economics of information systems by investigating six European organisations, two of which involved the beef supply chain, employing traceability programmes. ${ }^{4}$ Participants of this study, 'report that traceability often has internal production benefits from improved information and control of production even though traceability has generally been couched as a supply chain management issue driven by consumer demand' (Buhr, 2003, p. 17).

The only known economic study examining beef industry perceptions and preference in the USA is Bailey and Slade (2004) who conducted a survey to measure the level of support among a small sample of state veterinarians and producer group representatives. They examined how support for a specific animal identification proposal (US Animal Identification Plan, USAIP) varied based on concerns about animal health and the perceived costs and benefits accrued to different levels of the marketing chain. The study found that 'over $90 \%$ of state cattle producer association respondents indicated support for a national cattle identification program; whereas only $41 \%$ indicated that they supported the USAIP' (Bailey and Slade,

\footnotetext{
${ }^{3}$ Since 1 January 2002, the label contains information on the animal's origin, in particular where the animal was born, fattened, and slaughtered' (Gracia and Zeballos, 2005, p. 45).

${ }^{4}$ The two participating entities from the beef supply chain were Scase-Intentia/Gilde, a lamb, pork and beef supply chain in Norway; and Scotbeef, a beef production system in Scotland. The traceability systems employed by these entities extended from the feed manufacturing process through retail (Buhr, 2003).
} 
2004, p. 13). The lack of confidence in initial programmes, as indicated by the $41 \%$ in favour of the USAIP, documents the need for determining the most important attributes of voluntary traceability systems to aid in design and promotion of a more acceptable traceability system.

This article reports on the results of random utility multinomial logit and latent class logit models that examine producers' preferences for alternative traceability systems, using a national sample of producers characterised by preference heterogeneity. Incorporating and understanding preference heterogeneity provides valuable information on the distributional effects of traceability policy alternatives and better explains the current situation of partial $( \pm 30 \%)$ NAIS participation (USDA, 2008a). Accordingly, this study will be beneficial in future management of NAIS, and related animal traceability systems, as it provides insights into why producers participate in voluntary traceability systems and estimates producer welfare effects associated with mandating traceability.

\section{Methods}

As producer-level data are not publically available, collection of primary data was necessary. We developed a survey for US cow-calf producers to complete which provided us with the producer-level data necessary to estimate the logit models. The survey was designed to obtain information from US cow-calf producers regarding demographics, production practices, perceptions regarding traceability and potential beef traceability systems. ${ }^{5}$ Questions regarding producer's age, years raising beef cattle, estimated annual pretax income, NAIS premises registrations, marketing methods and number beef cows that calved were asked to better understand the characteristics of the cow-calf producers and their operations. More in-depth questions concerning cow-calf producers' perceptions of important issues and concerns to the US beef industry when designing a national, individual animal traceability system were then asked to capture the most important issues and concerns of cowcalf producers. A choice experiment (CE) was utilised to simulate real-life situations in which cow-calf producers choose between alternative traceability systems.

A total of 2000 (1998 effective) surveys were mailed to cow-calf producers (selected on an $n$th name basis by BEEF Magazine) throughout the USA. BEEF Magazine was used as its mailing list provided us the most extensive candidate sample available. Moreover, producer magazines have been used in other projects seeking producer-level survey data (Davis and Gillespie, 2007). The surveys were first reviewed by beef industry representatives and animal science faculty and updated to reflect their suggestions prior to mailing. A $\$ 1$ bill was included in the survey to potentially increase participation and response (Gregory, 2008). Post cards reminding producers to complete the survey were sent two weeks after the initial mailing with an Internet link to a survey being made available.

Summary statistics of survey respondents and their operations are provided in Table 1. The respondent pool provided 609 useable surveys $(30.48 \%$ effective response rate). ${ }^{6}$ Our sample has $41 \%$ (weighted data) indicating they have registered

\footnotetext{
${ }^{5}$ The survey instrument is available in Schulz (2008).

${ }^{6}$ Michigan respondents (5) were not included in the final dataset because of the mandatory nature of the state's individual, beef traceability system.
} 
Table 1

Summary statistics of survey respondents

\begin{tabular}{|c|c|c|c|}
\hline Variable & Description & $\begin{array}{l}\text { Unweighted } \\
\text { mean* }\end{array}$ & $\begin{array}{l}\text { Weighted } \\
\text { mean } \dagger\end{array}$ \\
\hline Age & Survey respondent's age? & $56.1376(13.0182)$ & $53.4940(15.7920)$ \\
\hline \multirow[t]{8}{*}{ Years } & $\begin{array}{c}\text { How many years } \\
\text { have you been raising } \\
\text { beef cattle? }\end{array}$ & & \\
\hline & $=1$ if less than 5 years & $0.0108(0.1035)$ & $0.0298(0.1699)$ \\
\hline & $=2$ if $6-10$ years & $0.0390(0.1935)$ & $0.0920(0.2890)$ \\
\hline & $=3$ if $11-15$ years & $0.0498(0.2175)$ & $0.0410(0.1983)$ \\
\hline & $=4$ if $16-20$ years & $0.0541(0.2263)$ & $0.0974(0.2965)$ \\
\hline & $=5$ if $21-25$ years & $0.0866(0.2812)$ & $0.0769(0.2665)$ \\
\hline & $=6$ if $26-30$ years & $0.1039(0.3052)$ & $0.1075(0.3098)$ \\
\hline & $=7$ if over 30 years & $0.6537(0.4758)$ & $0.5553(0.4970)$ \\
\hline \multirow[t]{7}{*}{ Income } & $\begin{array}{l}\text { Please estimate your } \\
\text { annual pretax household } \\
\text { income? }\end{array}$ & & \\
\hline & $=1$ if less than $\$ 25,000$ & $0.0507(0.2194)$ & $0.0988(0.2985)$ \\
\hline & $=2$ if $\$ 25,000-\$ 49,999$ & $0.1705(0.3761)$ & $0.1073(0.3096)$ \\
\hline & $=3$ if $\$ 50,000-\$ 74,999$ & $0.2143(0.4104)$ & $0.3294(0.4701)$ \\
\hline & $=4$ if $\$ 75,000-\$ 99,999$ & $0.1544(0.3613)$ & $0.1920(0.3940)$ \\
\hline & $=5$ if $\$ 100,000-\$ 124,999$ & $0.1106(0.3137)$ & $0.0918(0.2888)$ \\
\hline & $=6$ if $\$ 125,000$ or more & $0.2995(0.4581)$ & $0.1805(0.3846)$ \\
\hline \multirow{3}{*}{$\begin{array}{l}\text { NAIS } \\
\text { Premises }\end{array}$} & Are your operation's & & \\
\hline & $\begin{array}{l}\text { premise(s) currently } \\
\text { registered in NAIS? }\end{array}$ & & \\
\hline & $=1$ if yes; 0 otherwise & $0.4703(0.4992)$ & $0.4118(0.4922)$ \\
\hline \multirow[t]{2}{*}{ Auctions } & $\begin{array}{c}\text { Do you frequently } \\
\text { use local auctions to } \\
\text { market your operations } \\
\text { output? }\end{array}$ & & \\
\hline & $=1$ if yes; 0 otherwise & $0.6048(0.4889)$ & $0.7332(0.4423)$ \\
\hline Cows & $\begin{array}{c}\text { How many beef cows } \\
\text { that calved were } \\
\text { on hand } 1 \text { January } 2007 ?\end{array}$ & $299.2980(215.2550)$ & $63.5293(103.4640)$ \\
\hline
\end{tabular}

Notes: Values in parentheses are standard deviations.

*Sample means prior to application of weights that adjust sample characteristics to match NASS cow-calf operation numbers.

$\dagger$ Means calculated using weights that adjust sample characteristics to match NASS cow-calf operation numbers.

their premises with NAIS, which is reasonably consistent with current USDA estimates of $35 \%$ (USDA, 2009).

The random selection of producers to receive the survey allowed equal opportunity for selection regardless of participation in various farm organisations; however, given that BEEF Magazine subscribers traditionally have herd sizes greater than 100 animals, the sample was not expected to be completely representative of the diverse population of US cow-calf operations. 
As expected, cow-calf operations within our sample were larger than the general US cow-calf operation numbers as reported by the National Agriculture Statistics Service (NASS). To correct for the differences in the sample and the population, poststratification weights were created based on 2007 beef cows that calved per operation data from NASS. We chose this variable because beef cows that calved per operation are likely to be highly related to producers' demographics and production practices. Following Lusk and Rozan (2008) to create weights, we placed each respondent into one of five operation size categories. ${ }^{7}$ Weights were created by dividing the frequency of US cow-calf operations in each of the five size categories (as reported by NASS) by the fraction of cow-calf operations in the survey sample that fell in each of the five categories. To illustrate the effect of the weights on results, Table 1 reports weighted and unweighted means and standard deviations of producer' demographics and other variables used in the analysis. Once weights were applied to the data, the mean beef cows per operation match those of the US herd sizes. As the weighted statistics are more reflective of the actual population and corrected imbalances in sampling ratios from the general population to the sample, all results reported in the remaining analysis utilise the derived weights.

The survey contained a CE in which producers made choices between traceability systems with varying levels of premiums or discounts, managing entities and information required (e.g. age verification, production practice information, performance/genetic information and health records). Each respondent completed a $\mathrm{CE}$ designed to best resemble current and potential traceability systems within the beef industry while avoiding being overly complex for respondents (Norwood et al., 2006). Here, the primary purpose of the CE is to help determine producers' WTC, accept premiums or discounts, to voluntarily participate in a given traceability system. In other words, producers were asked how much they would need to be compensated in order to participate in a system with differing levels of participation requirements.

Choice experiments permit multiple attributes to be evaluated, thereby allowing researchers to estimate trade-offs between different alternatives (Lusk et al., 2003). An orthogonal fractional design (Kuhfeld et al., 1994) was used to select scenarios in which premiums/discounts are uncorrelated, and which allowed for identification of own-price and alternative specific effects. This process also allowed the CE to be of reasonable size for survey participants. Furthermore, following the lead of Tonsor et al. (2005), the CE was divided into blocks to ease respondent fatigue.

In this $\mathrm{CE}$, cow-calf producers were presented with a set of four different choice scenarios, each of which involved choosing a preferred alternative from three different traceability systems. ${ }^{8}$ The three traceability systems included: (i) NAIS Traceability; (ii) Advanced Traceability and (iii) No Traceability (see Appendix for descriptions). As recommended by Adamowicz et al. (1998), a no-choice option was presented to participants because this is an obvious option currently available to producers. Moreover, inclusion of a no participation scenario allows us to examine welfare effects of mandating traceability.

\footnotetext{
${ }^{7}$ Beef cows per operation categories included 1-49, 50-99, 100-499, 500-999 and 1,000+.

${ }^{8}$ The total number of scenarios in the $\mathrm{CE}$ was 20 which were blocked into five groups of four scenarios.
} 
The attributes included in the CE design were: (i) premium or discount per animal sold; (ii) managing entity and (iii) additional information required by Advanced Traceability participation (Appendix presents the complete set of CE instructions and attribute definitions). An example choice scenario included in the CE is shown in Table 2.

The CEs were hypothetical; however, our instructions specifically stated, 'Research studies have found people to overstate their willingness to participate (or accept discounts) in hypothetical situations. It is important that you make your selection as if you were actually facing these choices'. This cheap talk script was included before the scenarios, and has been shown to reduce hypothetical bias in CE research (Cummings and Taylor, 1999; Lusk, 2003).

The additional information requirements for Advanced Traceability participation were purposely not overly specific as doing so would have limited the scope of this study (e.g. required valuation of fewer attributes and/or levels) and reduced the applicability of certain practices to particular producers. However, we do acknowledge that different perceptions of producers in the requirements of these traceability system attributes probably affected their willingness to participate. As such, all of our conclusions are strictly based upon producer responses to the information provided to them. More work is needed to evaluate issues such as preferences for alternative methods of providing age verification or different levels of performance information.

\subsection{Choice modelling: Multinomial logit and latent class specifications ${ }^{9}$}

Data obtained through CEs has traditionally been analysed using multinomial logit (MNL) models (e.g. Lusk et al., 2003). Multinomial logits estimate producer random utility (Adamowicz et al., 1998; Lusk et al., 2003) which can be characterised by equation (1):

$$
U_{j t}=v_{j t}+\varepsilon_{j t}
$$

where $U_{j t}$ is the utility associated with alternative $j$ in choice scenario $t, v_{j t}$ is the systematic, observable component of utility determined by attributes and their values and $\varepsilon_{j t}$, is a random, unobservable component of logit models, independently and identically distributed over all alternatives and choice situations. A producer will

Table 2

Scenario example

\begin{tabular}{lccr}
\hline Attribute & NAIS traceability & Advanced traceability & No traceability \\
\hline Premium/discount (\$ per head) & $\$ 0.00$ & $\$ 7.50$ & $-\$ 15.00$ \\
Managing entity & Government & Private-Industry & \\
Additional Information & $\square$ & Performance/genetics & $\square$ \\
I choose... & $\square$ & $\square$ & $\square$ \\
\hline
\end{tabular}

\footnotetext{
${ }^{9}$ We also considered a random parameters logit model (Alfnes, 2004; Tonsor et al., 2005). Results were quantitatively similar and are not presented for brevity but are available upon request.
} 
choose alternative $j$ if $U_{j} \geq U_{k}$ for all $j \neq k$. So, the probability that alternative $j$ will be chosen is equal to the probability that the utility gained from its choice is greater than or equal to the utilities of choosing another alternative in the choice set. However, as these utilities contain a stochastic component, researchers can only describe the probability of producers choosing alternative $j$ as (Adamowicz et al., 1998; Boxall and Adamowicz, 2002):

$$
\operatorname{Prob}\{j \text { chosen }\}=\operatorname{prob}\left\{v_{j}+\varepsilon_{j} \geq v_{k}+\varepsilon_{k} ; j \neq k \forall j \in C\right\}
$$

where $C$ is the choice set of all possible alternatives. Assuming the random errors in equation (1) are independently and identically distributed across the $j$ alternatives and $N$ individuals with a type I extreme value distribution, Adamowicz et al. (1998), Boxall and Adamowicz (2002) and Lusk et al. (2003) have shown that the probability of a producer choosing alternative $j$ becomes:

$$
\operatorname{Prob}\{j \text { chosen }\}=\frac{\mathrm{e}^{\mu \beta X_{i}}}{\sum_{k \in C} \mathrm{e}^{\mu \beta X_{k}}}
$$

where $\mu$ is a scale parameter, which is inversely related to the variance of the error term and $\beta$ is a vector of parameters. According to Lusk et al. (2003) the scale parameter, $\mu$, is typically assumed equal to one because it is unidentifiable within any particular dataset. Assuming the systematic utility component $v_{j}$ is linear in the parameters and follows the generalised regression specification leads to:

$$
v_{j}=\beta_{1} x_{j 1}+\beta_{2} x_{j 2}+\cdots+\beta_{n} x_{j n}
$$

where $x_{j n}$ is the $n$th attribute value for alternative $j$ and $\beta_{n}$ is a vector of preference parameters associated with the $n$th attribute of the $j$ th alternative.

Multinomial logit models assume that all respondents share the same coefficients for a given attribute. That is, all respondents are assumed to have the same preferences for attributes, an assumption which may be unrealistic if producers' preferences are in fact heterogeneous.

A latent classification strategy assumes that producers can be separated into different classes such that producers within each class have homogeneous preferences but that preferences vary across producers from alternative classes (Boxall and Adamowicz, 2002). Thus, this process groups producers with relatively homogeneous preferences based on similarities in their utility functions.

Boxall and Adamowicz (2002) describe the latent class approach as assuming the existence of $s$ segments in a population where individual $n$ belongs to segment $s$ $(s=1, \ldots, s)$. The LCM estimates a utility function unique to each producer segment, which can be expressed:

$$
v_{n i \mid s}=\beta_{s} X_{n i}+\varepsilon_{n i \mid s} .
$$

In this expression the utility parameters are now segment specific. The probability of a producer choosing alternative $j$ is:

$$
\operatorname{Prob}\{j \text { chosen } \mid s\}=\frac{\mathrm{e}^{\mu_{s} \beta_{s} X_{i}}}{\sum_{k \in C} \mathrm{e}^{\mu_{s} \beta_{s} X_{k}}}
$$

where the $\beta$ s and $\mu$ s are segment-specific utility and scale parameters, respectively. 


\subsection{Willingness to change}

Individual coefficients estimated in random utility models have little interpretive value. However, in each model relative combinations of select coefficients provide economically meaningful insights into producer preferences. Accordingly, we follow Nahuelhual et al. (2004) and Rigby and Burton (2005) to identify how willing producers are to change traceability system attributes. In particular, the willingness of producers to change is calculated for each non-price traceability system attribute at the means of each model's explanatory variables. These calculations are generally given by.

$$
\text { Mean WTC }=\left.\frac{\mathrm{MU}}{\mathrm{MUI}}\right|_{\text {mean independent variables }}
$$

where MU is the mean marginal utility of traceability systems and system attributes and MUI is the marginal utility of income (proxied in our calculations with the premium or discount coefficient). Here, we use the term WTC to generally capture both willingness to pay (WTP) and willingness to accept (WTA) terms more common in the literature. We do this as our inclusion of a premium/discount variable makes calculation of both WTP and WTA estimates feasible and important. In short, WTP identifies the premium producers would pay to obtain a preferred attribute, whereas WTA identifies how much producers would accept as discounts to maintain their selection of a preferred attribute. Both WTP and WTA are calculated by equation (7).

To determine if the estimated average WTC estimates in each model are statistically different from zero, a Krinsky and Robb (1986) bootstrapping procedure was employed to develop confidence intervals on the WTC estimates. Bockstael and Strand (1987) have emphasised that the parameter estimates used to calculate welfare measures are themselves random variables; thus, the Krinsky-Robb technique used here to develop confidence intervals for the WTC measure accounts for the variability associated with all the estimated coefficients and is based directly on the logit specification for the choices of respondents. The Krinsky and Robb approach uses the information on the distribution of $\hat{\beta}$ contained in the variance-covariance matrix to approximate the distribution of WTC (Park et al., 1991).

\subsection{Voluntary participation forecast analysis}

Utilising equations (3) and (6) we can identify the probability of a producer choosing a given alternative under differing premium and discount pricing schemes. This allows us to investigate how selections change as premiums for Advanced Traceability participation or discounts for No Traceability appear as free-market incentives. Following Alfnes (2004) and Norwood et al. (2006), we use these probabilities as market share estimates.

\subsection{Producer welfare analysis}

In contrast to allowing the market to provide incentives, it is quite possible that the regulatory environment could change causing producers to adjust their traceability practices, regardless of market prices. For instance, it was originally intended that 
mandatory participation in NAIS was to be law (USDA, 2008a). Accordingly, a prudent question to ask is how producers would be impacted if No Traceability was no longer an allowed option?

We estimated the welfare effects producers would experience given two alternative scenarios: (i) removal of No Traceability and (ii) removal of both No Traceability and Advanced Traceability from producer choice sets. The first scenario represents the case of some level of traceability being mandated but not necessarily NAIS participation. This may reflect the USDA taking a position of cooperation with private traceability systems to increase overall traceability, without necessarily forcing NAIS participation. The second scenario reflects the possibility of non-NAIS traceability systems being viewed as either incompatible or insufficient and NAIS participation being mandated. Both scenarios restrict producers' choice sets and hence have welfare impacts worthy of evaluation.

Small and Rosen (1978) and Morey (1999) show that expected maximum utility from making a choice from a particular choice set is given by:

$$
\mathrm{CV}=\ln \left(\sum \mathrm{e}^{V j}\right)+K
$$

where $K$ is Euler's constant and $V_{j}$ is as previously defined. The welfare change that occurs when moving from one situation given by $\mathrm{CV}^{0}$ to a situation given by $\mathrm{CV}^{1}$ is:

$$
1 /(\text { Marginal utility of income }) \times\left[\left(\mathrm{CV}^{1}\right)-\left(\mathrm{CV}^{0}\right)\right] \text {. }
$$

The welfare measure accounts for the fact that producers are currently free to choose No Traceability and that actual choices are uncertain. These measures also capture producer valuations of autonomy and reflect more than simple differences in perceived costs (Key, 2005). This calculation represents that most producers would be willing to pay per choice occasion to face the choices in situation 1 vs. situation 0 (Lusk et al., 2006). Alternatively, this estimates the welfare impacts of forcing some traceability option (either NAIS or private) or forcing mandatory NAIS participation.

\section{Results}

Estimates of the multinomial logit and LCMs are provided in Table 3. The MNL model is rejected in favour of the LCM model (per likelihood ratio tests) but is presented as a benchmark comparison of results when assuming homogeneous preferences. When assuming homogeneity, the representative producer is found to prefer No Traceability to NAIS, and NAIS to Advanced Traceability, probably reflecting the perceived costs of the three options. However, interpretation of individual coefficients must be done with caution and is generally discouraged in random utility models (Scarpa and DelGiudice, 2004).

Following Boxall and Adamowicz (2002) for the identification of the number of classes to be used in this analysis, we minimised the Bayesian information criterion $(\mathrm{BIC})$, which leads to the three-class model. Inclusion of demographics in the LCM allows for further examination of the types of producers valuing NAIS, Advanced Traceability and No Traceability options differently. Producers with premises registered in NAIS are more likely to be in class 1 (47\% of producers) and prefer Advanced Traceability to NAIS and NAIS to No Traceability. Producers 


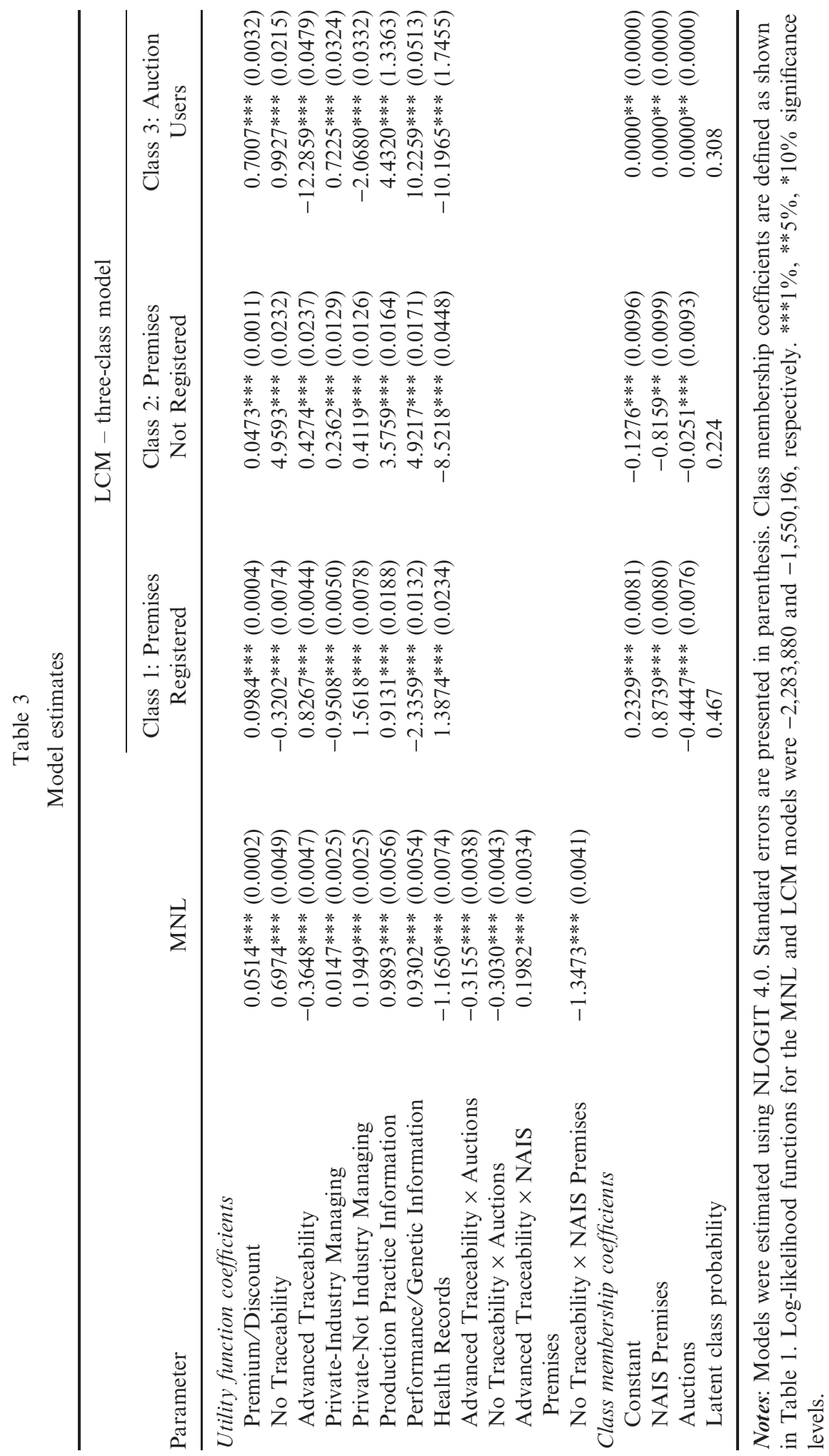


who do not have registered premises are more likely to be in class 2 (22\% of producers) and have a strong preference for No Traceability. Producers who use local auctions to market their cattle are more likely to be in class 3 (31\% of producers) and have a strong preference against Advanced Traceability. This leads us to label classes 1-3 as Premises Registered, Premises Not Registered and Auction Users, respectively.

We are particularly interested in estimates of producers' WTC estimates, which are provided in Table 4. The homogeneous MNL model implies, ceteris paribus, that the representative producer would accept a $\$ 2.53$ per animal discount before being indifferent between No Traceability and NAIS and would require a $\$ 10.59$ per animal premium to participate in the Advanced Traceability system rather than NAIS. The MNL model also suggests that producers must receive a premium of $\$ 0.57$ or $\$ 7.59$ per animal in a traceability system with private-industry management or private management outside the industry, to make them indifferent to having government management, respectively.

Representative producers must be paid $\$ 38.53$ and $\$ 36.23$ per animal, respectively, in a system seeking age verification to make them indifferent between providing age verification and providing production practice or performance/genetic information in an alternative system. An opposing result is that producers will accept discounts (relative to alternative traceability systems) of up to $\$ 45.37$ per animal before they will participate in a system requiring health records rather than a system solely requiring age verification. In summary, an implied preference ranking of these additional information attributes for the typical producer is: (i) production practice information, (ii) performance/genetic information, (iii) age verification and (iv) health records. Although these are marginal values for providing different types of additional information, little is currently known about the actual costs of their provision an issue worthy of future research.

The WTC estimates from the LCM reveal additional insights into preference heterogeneity. Class 1 (Premises Registered) producers would pay $\$ 2.96$ per animal to participate in NAIS rather than select No Traceability and would require a $\$ 7.71$ per animal premium to participate in the Advanced Traceability system rather than NAIS. These producers would need a premium of $\$ 31.75$ per animal to be indifferent to a traceability system that is managed by the government or privately outside the industry. Producers in this class would also require a \$18.57 and \$28.21 per animal premium to provide age verification as opposed to production practice information or health records, respectively.

Producers in class 2 (Premises Not Registered) are estimated to have the strongest preferences for No Traceability. In particular, the model suggests discounts of $\$ 118.52$ per animal would be accepted before producers would switch to NAIS from No Traceability. Producers in this class prefer managing entities to be private, either within or outside the industry and would require premiums of $\$ 9.98$ and $\$ 17.41$ per animal, respectively, to be indifferent to a traceability system being managed by the government. Furthermore, producers in this class are estimated to need $\$ 151.16$ and $\$ 208.05$ per animal premiums to provide age verification as opposed to production practice or performance/genetic information, respectively.

The sheer magnitudes of these estimates for class 2 warrant additional discussion. First, the overall utility function for these producers is consistent with a desire to not participate in traceability systems, to avoid government interaction, and to provide as little extra information as possible. This corresponds with the high 


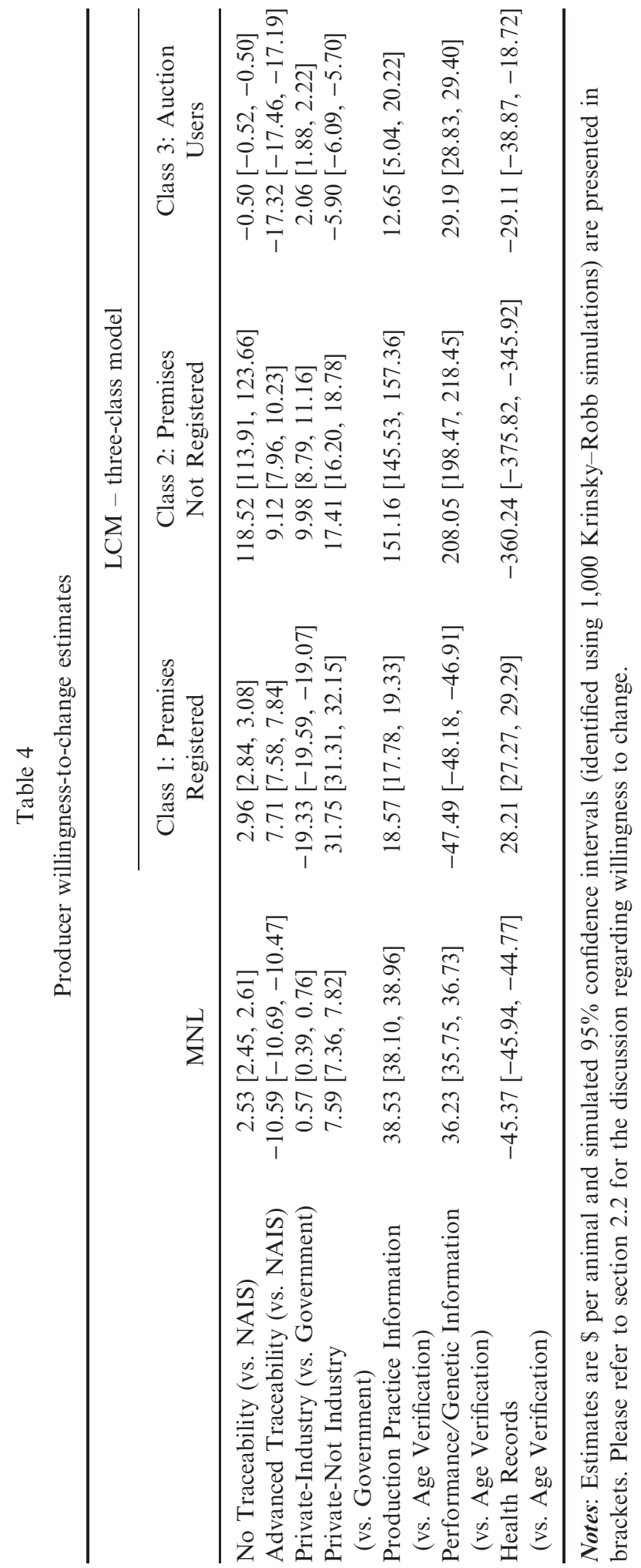


probability of these producers not having their premises currently registered with USDA (Table 3). These inferences may also reflect 'protest responses'. ${ }^{10}$ For instance, Boyle (2003) suggests respondents may provide protest answers in a strategic move hoping to change the provision of the good in question. In our context, producers in class 2 may be exaggerating their preferences with the goal of influencing policy they believe may be informed by this research. Although unable to identify the particular reasons underlying the magnitudes stated by these producers, we are confident that these producers strongly dislike the idea of traceability participation in general, and cooperation with government entities in particular.

The third set of producers (Auction Users) are estimated to have the strongest preferences for not adopting Advanced Traceability. In particular, the model suggests premiums of $\$ 17.32$ per animal would be necessary before producers would switch from NAIS to Advanced Traceability. Conversely, these producers are rather indifferent between NAIS and No Traceability participation ( $\$ 0.50$ per animal difference). These producers prefer the managing entity to be private and within the industry and would require a premium of $\$ 2.06$ per animal to be indifferent between private-industry and government management. Producers in this class would require $\$ 12.65$ and \$29.19 per animal premiums to provide age verification as opposed to production practice or performance/genetic information, respectively. Given a premium of $\$ 29.11$ per animal, these producers would be indifferent to providing health records or age verification.

In summary, cow-calf producers are notably heterogeneous in the preferences for traceability systems and their WTA discounts to sustain participation in their preferred traceability programs. To assess the implications of these producer preferences on the industry at the national level, we now turn to examining their impact on likely participation rates in different traceability systems as well as the producer welfare impacts of alternative policy scenarios.

\subsection{Forecasts of voluntary participation rates}

Premise registration, the foundation of NAIS, was originally targeted for $100 \%$ compliance by 2009 , but the USDA conceded that due to the voluntary nature of NAIS the original targets were unattainable (USDA, 2007). USDA (2008a) currently has goals for NAIS participation of $35 \%$ and $60 \%$ of the 2008 calf crop by October 2009 and October 2010, respectively. Without mandating, producers will be slower to adopt and fewer will adopt identification and tracing technology (Schroeder et al., 2009). Thus, the long-term goals of NAIS participation are probably unattainable, as slow and small adoption rates make it difficult, especially for smaller firms in industry, to know what direction to head in terms of adding or not adding animal identification and recording services (Schroeder et al., 2009).

To assess the viability of these goals, we first identify the forecasts implied by our models at the mean of all variables. Second, we consider varying the premium for Advanced systems and the discount for choosing No Traceability to examine how traceability choices vary given alternative free-market price incentives in the current legislative environment of voluntary traceability.

\footnotetext{
${ }^{10}$ There is an extensive literature on 'protest responses' in contingent valuation and CE applications. A solid review is provided by Meyerhoff and Liebe (2008) for interested readers.
} 
The MNL model is again presented as a benchmark comparison of forecast, as an example of homogeneous producer preferences. Using MNL estimates and holding all traceability attributes at their mean values (Figure 1) producers are 26.2\% likely to participate in $N A I S, 17.2 \%$ likely to participate in Advanced Traceability and $56.6 \%$ likely to choose No Traceability. It should be noted that this estimate of $26.2 \%$ NAIS participation is rather consistent with current USDA statistics (USDA, 2008a). The LCM estimates provide forecasts for distinct producer classes. Producers in classes $1-3$ are $21.2 \%, 0.4 \%$ and $90.4 \%$ likely to participate in NAIS, respectively, and $21.7 \%, 98.9 \%$ and $9.6 \%$ likely to choose No Traceability (Figure 1).

To assess how producers may update their traceability choices in a market characterised by different price incentives, we also examined increasing premiums in Advanced systems and discounts for choosing No Traceability. Figure 2 shows that the MNL model implies a \$27 per animal premium for Advanced Traceability participation in order to reach a goal of $60 \%$ traceability participation (either in NAIS or Advanced). ${ }^{11}$ On the other hand, Figure 3 shows that a $\$ 16$ per animal discount for not participating in any traceability system would achieve the $60 \%$ goal.

Utilising the LCM estimates and varying the premium for Advanced Traceability participation, Figure 4 shows that producers in class 1 would already have $75 \%$ participation in NAIS or an Advanced system with no premium at all; producers in class 2 would require a premium of $\$ 116$ per animal for participating in an Advanced system before $60 \%$ would be identified, whereas producers in class 3 already have $90 \%$ participation in NAIS or an Advanced system with no premium at all.

Varying the discount for non-participation in any traceability system (Figure 5) shows that producers in class 1 would have $73 \%$ participation in NAIS or an Advanced system with no discounts; producers in class 2 would need to be discounted $\$ 106$ per animal for non-participation before $60 \%$ would be identified, whereas producers in class 3 would only require discounts of $\$ 0.10$ per animal before the goal of $60 \%$ identified.

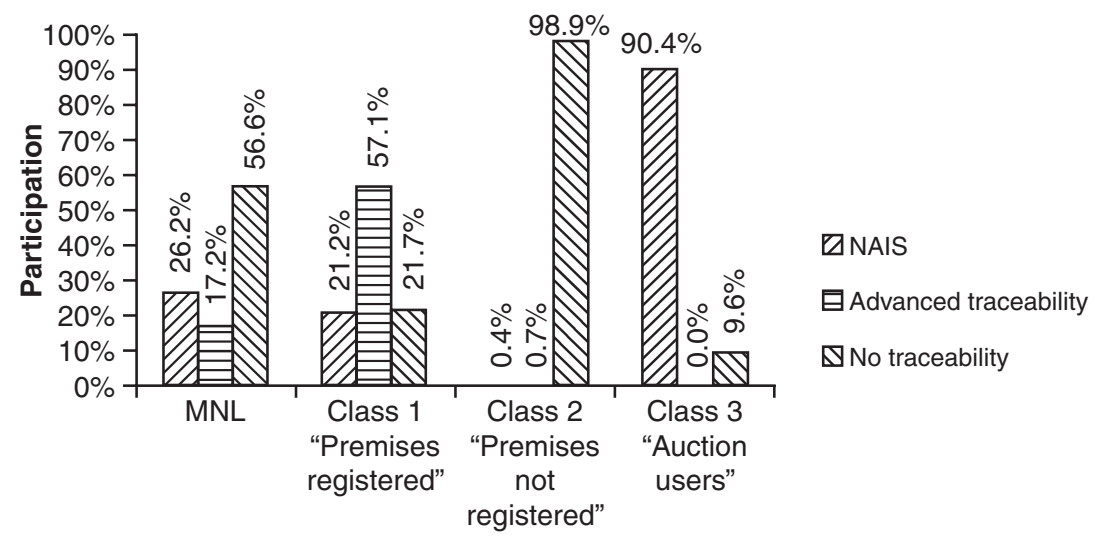

Figure 1. Mean participation rates of producers

\footnotetext{
${ }^{11}$ Here, we assume, particularly under voluntary NAIS regulation, that participation in either NAIS or Advanced Traceability systems would appease the USDA goal.
} 


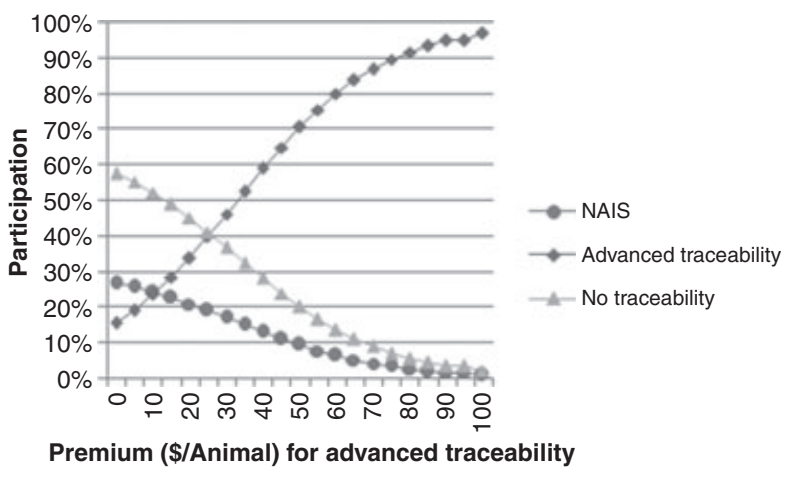

Figure 2. Participation rate vs. market premiums (MNL estimates)

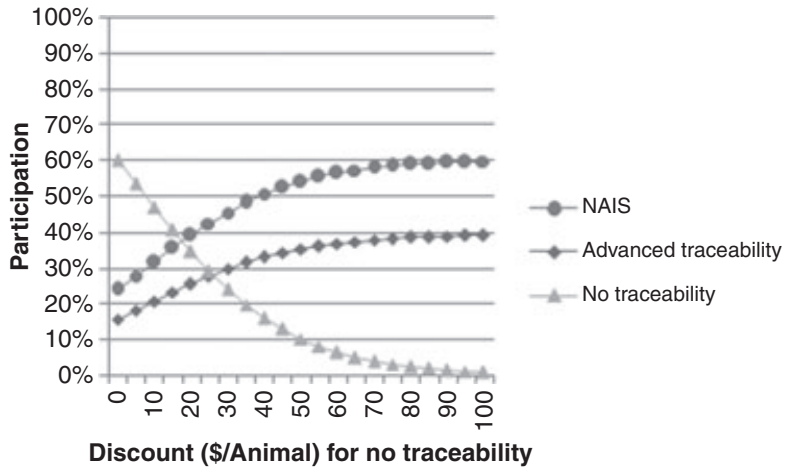

Figure 3. Participation rate vs. market discounts (MNL estimates)

Collectively, this suggests voluntary participation in traceability programmes deemed undesirable to the representative cow-calf producer may be accomplished by markets offering premiums for participation or penalties for non-participants. Our analysis also suggests that producers in classes 1 and 3 have preferences generally consistent with USDA's goals, whereas producers in class 2 are likely to strongly resist efforts to meet USDA's current traceability goals.

\subsection{Producer welfare effects}

Producer welfare effects were estimated reflecting the amount necessary to make a producer equally well-off in two alternative situations that cow-calf producers may face in future. More specifically, situations in which producers face all three traceability options (i.e. NAIS, Advanced and No Traceability) vs. situations in which the No Traceability option is removed or both No Traceability and Advanced Traceability are removed were considered. The latter case would be a situation of mandatory NAIS Traceability. These remain realistic possibilities, making them valid scenarios to consider.

Welfare estimates utilising the MNL model (Table 5) suggests removal of the No Traceability option results in an estimated welfare loss of $\$ 9.82$ per animal for the representative producer, whereas imposing mandatory NAIS generates a welfare 

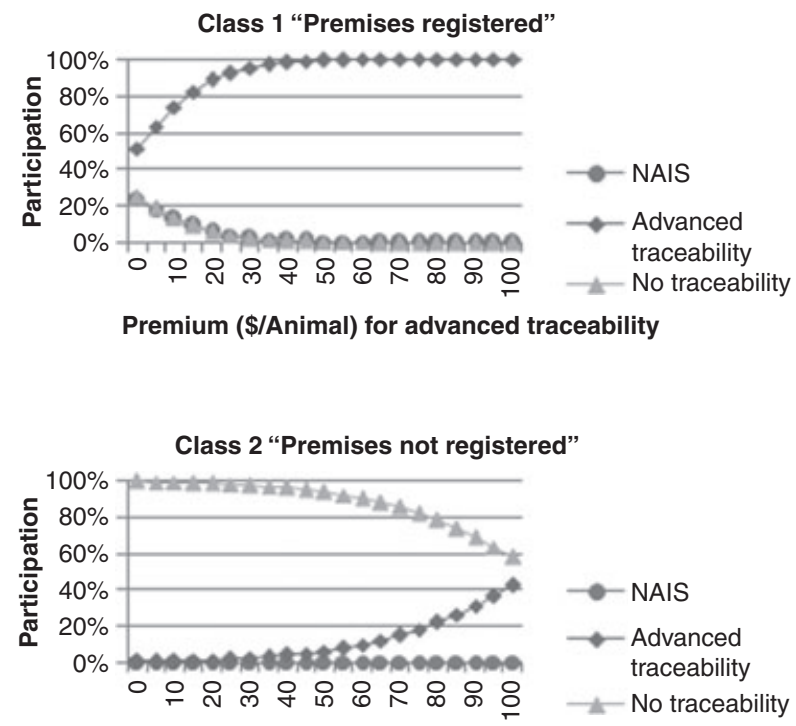

Premium (\$/Animal) for advanced traceability

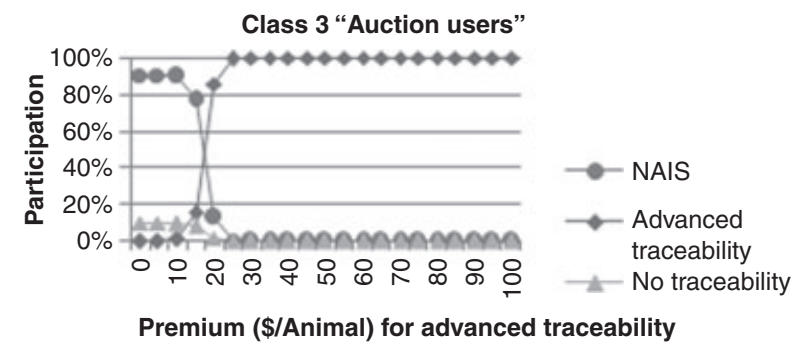

Figure 4. Participation rate vs. market premiums (LCM estimates)

loss of \$20.57 per animal. Utilising the LCM model (Table 5), the welfare estimates were calculated for three distinct producer classes. Producers in class 1 would experience a welfare loss of $\$ 2.32$ per animal if the No Traceability option was removed and face a welfare loss of $\$ 19.10$ per animal if NAIS was the only option available. Class 2 producers are far more negatively impacted by reduced choice sets. These producers face a welfare loss of $\$ 89.89$ per animal for the removal of No Traceability and a welfare loss of $\$ 118.82$ per animal for a situation in which only mandatory NAIS is available. ${ }^{12}$ Class 3 producers would have a welfare loss of $\$ 0.76$ per animal if the No Traceability option was removed or if the No Traceability and Advanced Traceability options were both removed.

Comparison of welfare effect estimates across the two models shows notable differences. The segmentation of the LCM reveals varying degrees of the welfare effects, as producers in class 1 experience relatively small impacts when only losing

\footnotetext{
${ }^{12}$ As previously noted, the welfare estimates for these producers may well reflect protest behaviour. Nonetheless, the substantial magnitude of these estimates relative to producers in other segments documents the diverse welfare impacts which would be experienced by producers with heterogeneous preferences.
} 

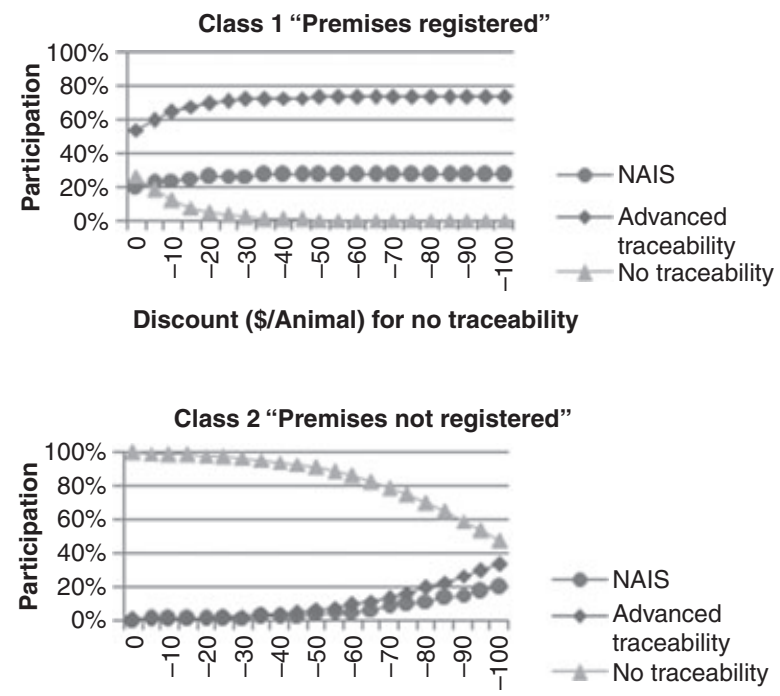

Discount (\$/Animal) for no traceability

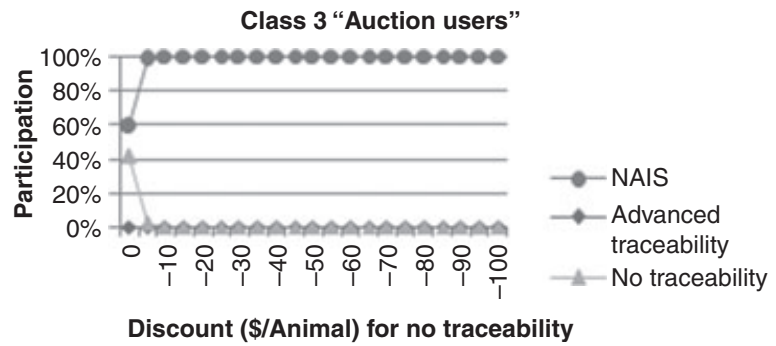

Figure 5. Participation rate vs. market discounts (LCM estimates)

Table 5

Welfare effects estimates

\begin{tabular}{lcccc}
\hline & & \multicolumn{3}{c}{ LCM - three-class model } \\
\cline { 3 - 5 } & MNL & $\begin{array}{c}\text { Class 1: Premises } \\
\text { Registered }\end{array}$ & $\begin{array}{c}\text { Class 2: Premises } \\
\text { Not Registered }\end{array}$ & $\begin{array}{c}\text { Class 3: Auction } \\
\text { Users }\end{array}$ \\
\hline Removal of & -9.82 & -2.32 & -89.89 & -0.76 \\
No Traceability & {$[-9.89,-9.72]$} & {$[-2.34,-2.30]$} & {$[-93.46,-86.66]$} & {$[-0.77,-0.75]$} \\
Option & -20.57 & -19.10 & -118.82 & -0.76 \\
Mandatory & {$[-20.76,-20.40]$} & {$[-19.29,-18.91]$} & {$[-123.98,-114.19]$} & {$[-0.77,-0.75]$} \\
NAIS & & & & \\
Traceability & & & & \\
\hline
\end{tabular}

Notes: Estimates are \$ per animal. Values in brackets are $95 \%$ confidence intervals, identified using 1,000 Krinsky-Robb simulations.

the No Traceability option, but experience notably larger effects once both the No and Advanced Traceability options are removed. Within class 3, producers' welfare effects are relatively small in both situations. Conversely, producers within class 2 
experience relatively large welfare effects for both situations that exceed those of the other two LCM classes and those suggested by the MNL. Collectively, these results provide further evidence for the importance of model specification and consideration of producer preference heterogeneity. Moreover, these estimates are consistent with the mixed success that USDA has had to date in obtaining voluntary participation in NAIS.

\section{Implications}

The results and associated inferences regarding producer preferences provide an improved understanding of how traceability systems should be designed and promoted in order to improve voluntary participation rates. To summarise the implications of the WTC findings, two specific cases that may benefit from this research are discussed. The first case would be a scenario of developing a voluntary traceability system that is fairly similar to NAIS in that there are limited 'additional information pieces' required for producer participation. The purpose of a heavily structured (e.g. little to no variability in the trade-off between participation requirements and per animal compensation) traceability system could be to enhance the entire industry's ability to quickly identify and contact animal premises, promote animal identification and develop animal movement and tracing capabilities. These goals would be consistent with those of animal health management and response objectives held by USDA in developing and promoting NAIS.

Alternatively, more advanced systems that enable producers or firms further down the supply chain to use traceability information could be designed as marketing tools. For instance, a traceability system could be designed to capture the production practice information most desired by a select consumer group. Provision of this information would require cooperation and compensation of all players in the supply chain, with benefits reflecting the perceived final market value of the information to consumers. For a producer this traceability information would give added value to the cattle they market, in exchange for their willing participation. For a retailer this traceability information provides value as consumers may be willing to pay for these added attributes.

Our results suggest that developers of a system who are primarily interested in achieving participation rate goals (e.g. as opposed to alternative national herd health goals held by USDA) can expect systems with managing entities being private and not within the industry to enhance participation by producers. Furthermore, given that NAIS implicitly has government management, these results suggest that producer participation may have been higher with private management. However, care should be taken in this assessment as the USDA, in managing NAIS, certainly has objectives beyond simply maximising voluntary participation rates (e.g. animal herd health surveillance and response ability enhancement). Nonetheless, the results indicate a trade-off of participation rate and managing entity does exist for cow-calf producers.

In designing a private traceability system, altering the composition of the additional information required for participation is found to significantly impact voluntary participation. Advanced systems that only require production practice information or performance/genetic information, as opposed to age verification, would be supported. Producers would require significant premiums to provide age verification as opposed to production practice information and performance/genetic 
information. As such, the cost of requiring producers possessing these preferences to provide age verification seem likely to outweigh the benefits of increasing the participation in many systems. Therefore, traceability system designers need to carefully outweigh the anticipated benefits of this age verification information (e.g. enhanced value of marketing verified younger animals) with the compensation that may be required to get producers to participate. Producers have a preference for providing age verification as opposed to health records. This suggests that for systems considering verification of animal health throughout the supply chain to be a higher priority than age verification, target marketing may be needed.

The welfare effect estimates of $\$ 89.89$ and $\$ 118.82$ per animal for removing the No Traceability option and imposing mandatory traceability, respectively, may be large enough that increasing support for traceability or mandatory traceability would not be feasible in class 2 (i.e. producers who do not have registered premises and hold a strong preference for No Traceability). Stated differently, these large estimates suggest that these producers will probably not be willing to voluntarily participate in any traceability system. A prerequisite of their participation may well be a market characterised by mandated traceability, either by the government of the private sector that simply chooses to no longer accept untraced animals. However, producers in class 2 only comprise $22 \%$ of the representative producers. Thus, it is conceivable that the USDA could increase the level of participation to $78 \%$ by targeting producers in classes 1 and 3. Participation in NAIS or advanced traceability systems could be improved by offering relatively small premiums to producers for participation in traceability systems. Alternatively, discounts for non-participation by the marketplace may achieve a similar increase in participation. Nonetheless, from an animal herd health perspective, it seems optimistic to assume that 'all animals are equal' in the need to be included in nationwide traceability systems. That is, having NAIS simply targeting the 'easiest $78 \%$ of producers' to meet enrolment goals may not be ideal from a national herd health and animal disease perspective.

The welfare effect estimates, and associated inferences regarding implications of producers' realising a reduced set of voluntary system options (e.g. being forced to participate in either Advanced Traceability and/or NAIS), provide an improved understanding of how requiring traceability or imposing mandatory NAIS affects producers differently.

\section{Conclusions}

With traceability becoming ever more important within the beef industry for verification of animal health as well as marketing purposes, the need for traceability systems that are attractive to producers as well as meet the goals that they were designed for is evident. Traceability systems that are most aligned with the preferences of cow-calf producers will enjoy higher voluntary participation. Subsequently, a majority of the past research has sought to analyse consumers' preferences towards voluntary traceability systems; however, there has been little research on producers' preferences towards these same traceability systems.

This article utilised models examining cow-calf producers' preferences for traceability systems and system attributes. Heterogeneity does exist between cow-calf producers and their preferences for traceability systems. Producers were found to be sensitive to price, managing entity and information requirements in comparing voluntary traceability systems. We also found voluntary participation in traceability 
programmes to be influenced by markets offering premiums for participation or penalties for non-participants. Furthermore, removal of traceability options contributes negatively to the economic welfare of all producers but especially those producers with strong preferences to avoid governmental interaction or provision of additional information about their operations.

This work should be beneficial to private entities interested in recruiting cow-calf producers into advanced traceability programmes. Results should also be valuable to USDA personnel in future resource allocations aimed at improving NAIS participation rates, in examining producer welfare effects of mandatory traceability regulations and other issues hinging on heterogeneous preferences of livestock producers. The welfare effects of alternative legislative adjustments provided here should be compared in future work examining the relationship with 'the cost of doing nothing', such as the industry-wide effects of not having traceability systems in place mitigating animal health and related risks (Tonsor and Schroeder, 2006). Such work should shed additional light on the inherent public good, industry-wide consequences of relying on a voluntary adoption system aimed at highly heterogeneous producers. Future work would be well served to examine other sectors (e.g. background or feedlot) of the cattle supply chain and other species (e.g. swine or poultry) at the heart of livestock traceability discussions in the USA. Moreover, the framework demonstrated here with US cow-calf producers could valuably be extended to livestock producers in other countries facing alternative national animal identification or traceability programmes. That is, producers in the European Union, Canada, Australia and Brazil each face different situations worthy of comparable investigation.

\section{References}

Adamowicz, W., Boxall, R., Williams, M. and Louviere, J. 'Stated preference approaches for measuring passive use values: Choice experiments and contingent valuation', American Journal of Agricultural Economics, Vol. 80, (1998) pp. 64-75.

Alfnes, F. 'Stated preferences for imported and hormone-treated beef: Application of a mixed logit model', European Review of Agricultural Economics, Vol. 31, (2004) pp. 19-37.

Bailey, D. 'Political economy of the U.S. cattle and beef industry: Innovation adoption and implications for the future', Journal of Agricultural and Resource Economics, Vol. 32, (2007) pp. 403-416.

Bailey, D. and Slade, J. 'Factors influencing support for a national animal identification system for cattle in the United States', Paper presented at AAEA annual meeting, Denver, CO, 1-4 August, 2004.

Bockstael, N. E. and Strand, I. E., Jr 'The effects of common sources of regression error on benefit estimates', Land Economics, Vol. 63, (1987) pp. 11-20.

Boxall, P. C. and Adamowicz, W. L. 'Understanding heterogeneous preferences in random utility models: A latent class approach', Environmental and Resource Economics, Vol. 23, (2002) pp. 421-446.

Boyle, K. J. 'Contingent valuation in practice', in P. A. Champ, K. J. Boyle and T. C. Brown (eds.) A Primer on Nonmarket Valuation (Dordrecht: Kluwer, 2003, 111-170).

Buhr, B. L. Traceability, Trade and COOL: Lessons from the EU Meat and Poultry Industry, International Agricultural Trade Research Consortium, Pullman. Working Paper. International Agricultural Trade Research Consortium no. 03-5, 2003. Available at http://purl.umn. edu/14577. Last accessed on 13 July 2009.

Cattle Network. Five Minutes With Dr. John Wiemers, USDA, APHIS, NAIS (2008). Available at: http://www.cattlenetwork.com/content.asp?ContentId $=194952$. Last accessed 5 February 2008. 
Cummings, R. G. and Taylor, L. O. 'Unbiased value estimates for environmental goods: A cheap talk design for the contingent valuation method', American Economic Review, Vol. 89, (1999) pp. 649-665.

Davis, C. G. and Gillespie, J. M. 'Factors affecting the selection of business arrangements by U.S. hog farmers', Review of Agricultural Economics, Vol. 29, (2007) pp. 331-348.

Dickinson, D. and Bailey, D. 'Meat traceability: Are U.S. consumers willing to pay for it?' Journal of Agriculture and Resource Economics, Vol. 27, (2002) pp. 348-364.

Dickinson, D. L., Hobbs, J. E. and Bailey, D. A Comparison of U.S. and Canadian Consumers' Willingness to Pay for Red-Meat Traceability, Paper presented at AAEA annual meeting. Montreal Canada, 27-30 July 2003.

Golan, E., Krissoff, B., Kuchler, F., Calvin, L., Nelson, K. and Price, G. Traceability in the US Food Supply: Economic Theory and Industry Studies. ERS For. Agr. Econ. Rep. 830 (Washington, DC: US Department of Agriculture, 2004).

Gracia, A. and Zeballos, G. 'Attitudes of retailers and consumers toward the EU traceability and labeling system for beef', Journal of Food Distribution Research, Vol. 36, (2005) pp. $45-56$.

Gregory, A. Optimal Economic Design of Mail Surveys: Influences of Response Rates and the Impact of Responses to a Second Mailing ( $\mathrm{PhD}$ dissertation; Kansas State University, 2008).

Key, N. 'How much do farmers value their independence?' Agricultural Economics, Vol. 33, (2005) pp. 117-126.

Krinsky, I. and Robb, A. L. 'On approximating the statistical properties of elasticities', Review of Economics and Statistics, Vol. 64, (1986) pp. 715-719.

Kuhfeld, W. F., Tobias, R. D. and Garratt, M. 'Efficient experimental design with marketing research applications', Journal of Marketing Research, Vol. 31, (1994) pp. 545-557.

Lusk, J. 'Effects of cheap talk on consumer willingness-to-pay for golden rice', American Journal of Agricultural Economics, Vol. 85, (2003) pp. 840-856.

Lusk, J. and Rozan, A. 'Public policy and endogenous beliefs: The case of genetically modified food', Journal of Agricultural and Resource Economics, Vol. 33, (2008) pp. 270-289.

Lusk, J., Roosen, J. and Fox, J. 'Demand for beef from cattle administered growth hormones or fed genetically modified corn: A comparison of consumers in France, Germany, the United Kingdom, and the United States', American Journal of Agricultural Economics, Vol. 85, (2003) pp. 16-29.

Lusk, J. L., Norwood, F. B. and Pruitt, J. R. 'Consumer demand for a ban on antibiotic drug use in pork production', American Journal of Agricultural Economics, Vol. 88, (2006) pp. 1015-1033.

Meyerhoff, J. and Liebe, U. 'Do protest responses to a contingent valuation question and a choice experiment differ?' Environmental Resource Economics, Vol. 39, (2008) pp. 433-446.

Morey, E. R. 'TWO RUMS un CLOAKED: Nested-logit models on site choice and nestedlogit models of participation and site choice', in J. A. Herriges and C. L. Kling (ed.), Valuing Recreation and the Environment (Northampton, MA: Edward Elgar, 1999, 65-120).

Murphy, R. G. L., Pendell, D. L., Morris, D. L., Scaga, J. A., Belk, K. E. and Smith, G. C. 'Review: Animal identification systems in North America', Professional Animal Scientist, Vol. 24, (2008) pp. 277-286.

Murphy, R. G. L., Pendell, D. L. and Smith, G. C. 'Lessons from the Canadian cattle industry for developing the National Animal Identification System', International Food and Agribusiness Management Review, Vol. 12, (2009) pp. 1-18.

Nahuelhual, L., Loureiro, M. L. and Loomis, J. 'Using random parameters to account for heterogeneous preferences in contingent valuation of public open space', Journal of Agricultural and Resource Economics, Vol. 29, (2004) pp. 537-552.

Norwood, F. B., Winn, C., Chung, C. and Ward, C. E. 'Designing a voluntary beef checkoff', Journal of Agricultural and Resource Economics, Vol. 31, (2006) pp. 74-92. 
Park, T., Loomis, J. and Creel, M. 'Confidence intervals for evaluating benefits from dichotomous choice contingent valuation studies', Land Economics, Vol. 67, (1991) pp. 64-73.

Rigby, D. and Burton, M. 'Preference heterogeneity and GM food in the UK', European Review of Agricultural Economics, Vol. 32, (2005) pp. 269-288.

Scarpa, R. and DelGiudice, T. 'Market segmentation via mixed logit: Extra virgin olive oil in urban Italy', Journal of Agricultural and Food Industrial Organization, Vol. 2, (2004) pp. 118.

Schroeder, T. C., Blasi, D. A., Brester, G. W., Crosby, C., Dhuyvetter, K. C., Freeborn, J., Pendell, D. L., Smith, G. C., Stroade, J. and Tonsor, G. T. Benefit Cost Analysis of the National Animal Identification System (2009). Report for US Department of Agriculture, Animal and Plant Health Inspection available at: http://animalid.aphis.usda.gov/nais/ naislibrary/documents/plans_reports/Benefit_Cost_Analysis_NAIS.pdf. Last accessed on 20 May 2009.

Schulz, L. L. Cow-Calf Producer Preferences for Voluntary Traceability Systems and System Attributes (MS Thesis: Michigan State University, 2008).

Schulz, L. L. and Tonsor, G. T. 'ID feedback', BEEF Magazine, Vol. August, (2008) pp. 5254.

Small, K. A. and Rosen, H. S. 'Applied welfare economics with discrete choice models', Econometricia, Vol. 49, (1978) pp. 43-46.

Smith, G. C., Tatum, J. D., Belk, K. E., Scanga, J. A., Grandin, T. and Sofos, J. N. 'Traceability from a U.S. perspective', Meat Science, Vol. 71, (2005) pp. 174-193.

Souza Monteiro, D. M. and Caswell, J. A. The Economics of Implementing Traceability in Beef Supply Chains: Trends in Major Producing and Trading Countries (Amherst, MA: WP-06 Department of Resource Economics, University of Massachusetts, June 2004).

Tonsor, G. T. and Schroeder, T. C. 'Livestock identification: Lessons for the U.S. beef industry from the Australian system', Journal of International Food and Agribusiness Marketing, Vol. 18, (2006) pp. 103-118.

Tonsor, G. T., Schroeder, T. C., Fox, J. A. and Biere, A. 'European preferences for beef steak attributes', Journal of Agricultural and Resource Economics, Vol. 30, (2005) pp. 367380 .

US Department of Agriculture, Animal and Plant Health Inspection Service. National Animal Identification System (NAIS) - A User Guide and Additional Information Resources (Washington, DC: USDA, December 2007).

US Department of Agriculture, Animal and Plant Health Inspection Service. A Business Plan to Advance Animal Disease Traceability (Washington, DC: USDA, September 2008a).

US Department of Agriculture, Animal and Plant Health Inspection Service. USDA's 840 Animal Identification Solution Offers Producers One Number with Many Uses (Washington, DC: USDA, December 2008b).

US Department of Agriculture, Animal and Plant Health Inspection Service. Premise Registration Update (2009). Statistics available at: http://animalid.aphis.usda.gov/nais/premises_ id/update.shtml. Last accessed 17 July 2009.

\section{Appendix: Instructions and description provided to choice experiment respondents}

Following are four scenarios, each containing three different options for you to select from where two options are voluntary traceability systems you could participate in. These two systems would require you to: (i) provide basic contact information on your farm/premises and (ii) individually identify your livestock (prior to any sales transactions or movement to other premises) using approved radio frequency identification devices (RFID). The third option (No Traceability) is an alternative where you choose not to participate in either of the two presented 
traceability systems. For your information in interpreting the alternative traceability options please carefully read the following descriptions:

NAIS Traceability: refers to the National Animal Identification System (NAIS).

- The NAIS program consists of three components:

- Premise registration requires you to provide basic contact information.

- Animal identification provides you with a uniform numbering system for identifying your animals and linking them to a birthplace/premises of origin.

- Animal tracing allows you to choose an animal tracking database (owned and operated by private industry groups or States) and report certain animal movements that might pose a significant risk of disease transmission.

- USDA ensures producers that it will protect private information from disclosure.

Advanced Traceability: Same basic participation requirements as NAIS Traceability but also requires additional information which may include:

- Age Verification

- Production Practice Information (e.g. growth hormones and grass-fed diets)

- Performance/Genetic Information

- Health Certifications/Vaccinations Records

- Random verification audits would be required to further validate consistency between on-farm practices and information maintained within the traceability system.

The entity managing each traceability system may take one of three forms:

- Government: entity such as the USDA;

- Private-Industry: entity specialises in traceability specifically for the beef industry;

- Private-Not Industry: entity specialises in traceability for multiple livestock species.

In addition to differences in requirements and goals of these alternatives, these options differ in terms of the premium or discount (per head sold) you would receive by selecting that alternative. These price adjustments to the market price range from discounts of up to $\$ 15$ per head to premiums of up to $\$ 15$ per head. Negative numbers indicate discounts and positive numbers indicate premiums. 
lowa State University does not discriminate on the basis of race, color, age, religion, national origin, sexual orientation, gender identity, genetic information, sex, marital status, disability, or status as a U.S. veteran. Inquiries can be directed to the Director of Equal Opportunity and Compliance, 3280 Beardshear Hall, (515) 294-7612. 